\title{
An Examination of the Antioxidant Capacity, Antibacterial Activity and Toxicity of Commercial Kale and Spirulina Powders
}

\author{
Clémence Blanc ${ }^{1,2}$, Ian Edwin Cock $\mathbf{k}^{1,3, *}$ \\ 'Environmental Futures Research Institute, Griffith University, Brisbane, AUSTRALIA. \\ ${ }^{2}$ School of Biology, Ecole de Biologie Industrielle (EBI), Cergy, FRANCE. \\ ${ }^{3}$ School of Environment and Science, Griffith University, Brisbane, AUSTRALIA.
}

\begin{abstract}
Introduction: The development of antibiotic resistant bacteria has resulted in treatment failure for the current antibiotic regimen against many bacteria. A corresponding decrease in the development of new antibiotic therapies has highlighted the urgent need for the discovery of new antibiotics. An examination of 'superfoods' is an attractive option due to the high antioxidant capacities and beneficial secondary compounds reported in many 'superfoods'. This study was undertaken to test kale and spirulina extracts for the ability to inhibit the growth of a panel of bacterial pathogens of human importance. Methods: Commercially sourced kale and spirulina powders were extracted and tested for antimicrobial activity using modified disc diffusion and liquid dilution MIC methods. Toxicity was evaluated using an Artemia franciscana nauplii bioassay. Results: The methanolic and aqueous extracts of kale and spirulina displayed noteworthy growth inhibitory activity against $P$. mirabilis. The aqueous spirulina extract was a particularly good inhibitor of $P$. mirabilis, with MIC values as low as $220 \mu \mathrm{g} / \mathrm{mL}$. In contrast, all extracts were ineffective or of low inhibitory activity against all other bacteria tested. All extracts were
\end{abstract}

non-toxic in the Artemia nauplii bioassay, confirming their suitability as natural antibacterial therapies. Conclusion: These studies indicate that aqueous kale and spirulina extracts are promising inhibitors of $P$. mirabilis growth and may be useful in the prevention and treatment of rheumatoid arthritis, as well as other diseases caused by that bacterium.

Key words: Antibacterial activity, Natural therapies, Superfood, Brassica oleracea, Arthrospira, Artemia, Toxicity.

\section{Correspondence:}

Dr. Ian Edwin Cock

'School of Environment and Science, Nathan Campus, Griffith University, 170 Kessels Rd, Nathan, Brisbane, Queensland, AUSTRALIA.

${ }^{3}$ Environmental Futures Research Institute, Griffith University, 170 Kessels Rd, Nathan, Brisbane, Queensland, AUSTRALIA.

Phone no: +61 737357637

E-mail: i.cock@griffith.edu.au

DOI: $10.5530 / p c .2021 .1 .10$

\section{INTRODUCTION}

Plants have been used for thousands of years as medicines for treating a variety of different diseases (including fighting bacterial pathogens) by most, if not all civilisations globally. Indeed, the ability of plant extracts to block the growth of pathogenic bacteria has become a focus of substantial recent study. ${ }^{1-5}$ Much of the research into traditional medicinal plant use has focused on Asian, ${ }^{6-8}$ African, ${ }^{9-11}$ Middle Eastern ${ }^{12-14}$ and South American ${ }^{15}$ plants. However, despite the potential of plants to provide us with useful pharmaceutical agents, the field is still relatively poorly studied. Only an estimated $5-10 \%$ of the approximately 300,000-500,000 plant species worldwide have been screened for one or more bioactivities. ${ }^{9}$

The development of new antibiotic therapies is particularly urgent. The recent establishment of bacterial pathogens that are either extremely (XDR) or totally resistant (TDR) to common clinically used antibiotics ${ }^{16}$ has resulted in the need to develop new and effective antibiotic chemotherapies. There are now limited therapeutic options for many diseases caused by bacterial pathogens and the situation is expected to worsen in the future as bacteria exchange resistance genes. Indeed, the development of alternative antibacterial treatment modalities has become crucial and is considered by the World Health Organisation (WHO) to be one of the most serious challenges facing medical science. ${ }^{17}$ For reasons reviewed elsewhere, ${ }^{16}$ it is unlikely that the previous methods of antibiotic discovery/development will be as successful in the future and new treatment modalities are urgently required. Traditional medicines and herbal remedies have great potential for antimicrobial drug development and there has recently been a substantial increase in interest in this field. ${ }^{18-32}$

The consumption of 'superfoods' may be beneficial to human health, both in healthy individuals and in people suffering from disease. These foods have high levels of one or more important dietary components and may provide necessary nutrients and macromolecules to assist in maintaining a healthy nutritional balance, thereby decreasing the occurrence of disease. This maybe achieved in a number of ways, including boosting the individual's immune system, increasing metabolism and enhancing cellular protection mechanisms. Foods with high antioxidant contents may be particularly beneficial as high antioxidant levels assist in preventing the development of degenerative diseases such as cancer. ${ }^{33}$ Cardiovascular diseases, ${ }^{34}$ neural degeneration, ${ }^{35}$ diabetes and obesity. ${ }^{36}$ Phenolic phytochemicals are generally strong antioxidants. ${ }^{37}$ Their primary action involves the protection of cell constituents against oxidative damage through the scavenging of free radicals, thereby averting their deleterious effects on nucleic acids, proteins, and lipids in cells. ${ }^{37}$ Furthermore, 'superfoods' may contain high levels of secondary metabolites which may directly target bacterial pathogens, thereby preventing and treating pathogen infections. Therefore, superfoods may be good targets for screening for new antibacterial chemotherapies.

Brassica oleracea L. (commonly known as kale) is described as a 'superfood' due to its high levels of antioxidant vitamins. It is particularly rich in Vitamins $\mathrm{A}, \mathrm{C}, \mathrm{B}_{1}, \mathrm{~B}_{2}, \mathrm{~B}_{6}$, E, folate and pantothenic acid. ${ }^{38}$ It is also a rich source of several important dietary minerals, including iron, calcium, potassium, phosphates and manganese. Spirulina is an edible biomass of three species of cyanobacterium: Arthrospira platensis, Arthrospira fusiformis and Arthrospira maxima. It is a particularly rich source of protein (up to $70 \%$ of the dry weight), and also contains high levels of Vitamins $B_{1}, B_{2}, B_{6}$, manganese and iron. ${ }^{38}$ It is also rich in the fatty acids, gamma-linolenic acid, alpha-linolenic acid, linoleic acid, stearidonic acid, eicosapentaenoic acid (EPA), docosahexaenoic acid (DHA) and arachidonic acid, yet contains no detectable levels 
of Omega-3 fatty acids. The high contents of antioxidant vitamins and minerals of these two 'superfoods' makes them good targets for screening against bacterial pathogens that cause disease in humans. This study was undertaken to screen extracts produced from commercial kale and spirulina food additives against bacterial pathogens. The toxicity of the extracts was also determined to further evaluate their suitability for therapeutic use.

\section{MATERIALS AND METHODS}

\section{Plant material and extraction}

Commercially produced kale and spirulina food supplements were obtained from Nature's Way, Australia as pure dried powders. Individual $1 \mathrm{~g}$ masses of the dried plant material was extracted extensively in $50 \mathrm{~mL}$ methanol, deionised water or ethyl acetate for $24 \mathrm{~h}$ at $4^{\circ} \mathrm{C}$ with gentle shaking. All solvents were purchased from Ajax Fine Chemicals, Australia and were analytical (AR) grade. The extract was filtered through filter paper (Whatman No. 54) under vacuum followed by drying by rotary evaporation. The resultant pellet was dissolved in $5 \mathrm{~mL}$ deionised water (containing $1 \%$ DMSO), passed through $0.22 \mu \mathrm{m}$ filter (Sarstedt) and stored at $4^{\circ} \mathrm{C}$.

\section{Qualitative phytochemical studies}

Phytochemical analysis of the kale and spirulina extracts for the presence of saponins, phenolic compounds, flavonoids, phytosteroids, triterpenoids, cardiac glycosides, anthraquinones, tannins and alkaloids was conducted using standard assays. ${ }^{39-41}$

\section{Antioxidant capacity}

The antioxidant capacity of each extract was assessed using the DPPH free radical scavenging method ${ }^{42}$ with modifications. Briefly, DPPH solution was prepared fresh each day as a $400 \mu \mathrm{M}$ solution by dissolving DPPH (Sigma) in AR grade methanol (Ajax, Australia). A $2 \mathrm{~mL}$ aliquot of each extract was evaporated, and the residue resuspended in $2 \mathrm{~mL}$ of methanol. Each extract was added to a 96 well plate in 5, 10, 25, 50, $75 \mu \mathrm{L}$ volumes in triplicate. Methanol was added to each well to give a volume of $225 \mu \mathrm{L}$. A volume of $75 \mu \mathrm{L}$ of the fresh DPPH solution was added to each well to give a total reaction volume of $300 \mu \mathrm{L}$. Ascorbic acid was prepared fresh and examined across the range $0-25 \mu \mathrm{g}$ per well as a reference and the absorbances were recorded at $515 \mathrm{~nm}$. All tests and controls were performed in triplicate. The antioxidant capacity based on DPPH free radical scavenging ability was determined for each extract and expressed as $\mu \mathrm{g}$ ascorbic acid equivalents per gram of original plant material extracted.

\section{Antibacterial screening}

\section{Test micro-organisms}

All media was purchased from Oxoid Ltd., Australia. The reference strains of A. baylyi (ATCC21721), Klebsiella pneumoniae (ATCC31488), Proteus mirabilis (ATCC21721), Proteus vulgaris (ATCC21719) and Pseudomonas aeruginosa (ATCC39324) were purchased from American Tissue Culture Collection (ATCC), USA. Clinical isolate microbial strains of Alcaligenes feacalis, Bacillus cereus, Enterobacter aerogenes, Enterococcus faecalis, Escherichia coli, Klebsiella pneumonia, Proteus mirabilis and Pseudomonas aeruginosa were obtained from Ms Michelle Mendell and Ms Jane Gifkins, Griffith University. All stock cultures were subcultured and maintained in nutrient broth at $4^{\circ} \mathrm{C}$.

\section{Evaluation of antimicrobial activity}

Antimicrobial activity of the kale and spirulina extracts was determined using a modified disc diffusion assay ${ }^{43-46}$ Briefly, $100 \mu \mathrm{L}$ of the each bacterial suspension in $\log$ phase was spread onto individual nutrient agar plates and the extracts were tested for antibacterial activity using $6 \mathrm{~mm}$ sterilised filter paper discs. The discs were each infused with $10 \mu \mathrm{L}$ of the individual plant extract, allowed to dry and placed onto the inoculated plates. The plates were allowed to stand at $4^{\circ} \mathrm{C}$ for $2 \mathrm{~h}$ before incubation at $37^{\circ} \mathrm{C}$ for $24 \mathrm{~h}$. The diameters of the zones of inhibition (ZOIs) were measured to the closest whole millimetre. Each assay was performed three times in triplicate $(n=9)$. Mean values $( \pm$ SEM) are reported in this study. Standard discs of ampicillin $(10 \mu \mathrm{g})$ and chloramphenicol $(10 \mu \mathrm{g})$ were obtained from Oxoid, Australia and were used as positive controls to compare antibacterial activity. Filter discs infused with $10 \mu \mathrm{L}$ of distilled water were used as a negative control.

\section{Minimum inhibitory concentration (MIC) determination}

The minimum inhibitory concentration for each extract was determined using liquid dilution MIC assays and solid phase agar disc diffusion assays.

\section{Microplate liquid dilution MIC assay}

A standard liquid dilution MIC assay ${ }^{15}$ was used to evaluate the bacterial growth inhibitory activity of the extracts and conventional antibiotics. Briefly, log phase bacterial cultures were diluted to produce a McFarlands inoculation culture. A $100 \mu \mathrm{L}$ volume of sterilized nutrient broth was dispensed into all wells of a 96 well micro-titre plate. A volume of $100 \mu \mathrm{L}$ of the plant extracts or conventional antibiotics was subsequently dispensed into separate wells of the top row of the plate. A negative control (nutrient broth), sterile control (broth without bacteria) and a sample-free culture control (to ensure the media was capable of supporting microbial growth) were also included on all plates. Each test sample or control was serially diluted down each column on the plate by doubling dilution. The assay culture inoculum $(100 \mu \mathrm{L}$, containing approximately $1 \times 10^{6}$ colony forming units $(\mathrm{CFU}) / \mathrm{mL}$ ) was then added to all wells except the sterile control wells and incubated overnight at $37^{\circ} \mathrm{C}$. p-Iodonitrotetrazolium violet (INT, Sigma-Aldrich, Australia) was dissolved in sterile deionised water to a concentration of $200 \mu \mathrm{g} /$ $\mathrm{mL}$. A $40 \mu \mathrm{L}$ volume of the INT solution was added into all wells and the plate was incubated for a further $6 \mathrm{hr}$ at $37^{\circ} \mathrm{C}$. The MIC was visually determined as the lowest dose at which colour development was inhibited.

\section{Disc diffusion MIC assay}

The minimum inhibitory concentration (MIC) of each extract was also quantified by disc diffusion assay. ${ }^{43-46}$ Graphs of the zone of inhibition (ZOI) versus ln concentration were plotted and MIC values were calculated by linear regression.

\section{Artemia franciscana nauplii toxicity screening}

Toxicity was tested using an adapted Artemia franciscana nauplii lethality assay. ${ }^{47-49}$ Briefly, A. franciscana nauplii were incubated in the presence of the extracts, reference toxin $(1 \mathrm{mg} / \mathrm{mL}$ potassium dichromate) or artificial seawater (negative control) at $25 \pm 1^{\circ} \mathrm{C}$ under artificial light. All treatments were performed three times, each with internal triplicates $(n=9)$. The number of dead were counted in each well at $24 \mathrm{~h}$ then sacrificed and the total number of nauplii in each well were counted and used to calculate the $\%$ mortality per well. LC $_{50}$ values were calculated for each treatment using probit analysis. 


\section{Statistical analysis}

Data are expressed as the mean \pm SEM of three independent experiments with internal triplicates $(n=9)$. One way ANOVA was used to calculate statistical significance between control and treated groups, with a $P$ value $<0.01$ considered to be statistically significant.

\section{RESULTS}

\section{Liquid extraction yields, qualitative phytochemical screening and antioxidant capacity}

Extraction of $1 \mathrm{~g}$ of dried plant material with various solvents yielded dried plant extracts ranging from approximately $5 \mathrm{mg}$ to $355 \mathrm{mg}$ (Table 1). The dried extracts were resuspended in $10 \mathrm{~mL}$ of deionised water (containing 1\% DMSO), resulting in the extract concentrations shown in Table 1. Phytochemical studies (Table 1) show that methanol and water extracted the widest range and largest amount of phytochemicals in this study. The methanolic and aqueous extracts of both kale and spirulina contained high levels of total phenolics (water soluble and insoluble phenolics) and flavonoids, as well as lower levels of tannins. The ethyl acetate extracts contained similar classes of phytochemicals, although at substantially reduced relative abundances. All extracts were completely devoid of detectable levels of alkaloids, anthraquinones,

Table 1: The mass of dried extracted material, the concentration after resuspension in deionised water, qualitative phytochemical screenings and antioxidant contents of kale and spirulina extracts.

\begin{tabular}{|c|c|c|c|c|c|c|c|}
\hline & & M & w & E & M & w & $\mathrm{E}$ \\
\hline \multirow{8}{*}{ Phenolics } & $\begin{array}{c}\text { Mass of extract } \\
(\mathrm{mg})\end{array}$ & 245 & 230 & 80 & 155 & 355 & 50 \\
\hline & $\begin{array}{c}\text { Concentration } \\
\text { of extract (mg/ } \\
\mathrm{mL})\end{array}$ & 24.5 & 23 & 8 & 15.5 & 35.5 & 5 \\
\hline & Total phenolics & +++ & +++ & + & +++ & +++ & + \\
\hline & $\begin{array}{l}\text { Water soluble } \\
\text { phenolics }\end{array}$ & +++ & +++ & + & +++ & +++ & + \\
\hline & $\begin{array}{l}\text { Water insoluble } \\
\text { phenolics }\end{array}$ & +++ & +++ & + & +++ & +++ & - \\
\hline & $\begin{array}{l}\text { Cardiac } \\
\text { glycosides }\end{array}$ & - & - & - & - & - & - \\
\hline & Saponins & + & + & - & - & + & - \\
\hline & Triterpenes & - & - & - & - & - & - \\
\hline \multirow{4}{*}{ Alkaloids } & Phytosterols & - & - & - & - & - & - \\
\hline & Meyer test & - & - & - & - & - & - \\
\hline & Wagner test & - & - & - & - & - & - \\
\hline & Flavonoids & +++ & +++ & ++ & +++ & ++ & + \\
\hline \multirow{4}{*}{ Anthraquinones } & Tannins & + & ++ & - & + & + & - \\
\hline & Free & - & - & - & - & - & - \\
\hline & Combined & - & - & - & - & - & - \\
\hline & $\begin{array}{l}\text { Antioxidant } \\
\text { capacity }\end{array}$ & 10.49 & 8.78 & - & 1.09 & 6.01 & - \\
\hline
\end{tabular}

+++ indicates a large response; ++ indicates a moderate response; + indicates a minor response; - indicates no response in the assay. $\mathrm{AA}=$ ascorbic acid. Antioxidant capacity determined by DPPH reduction (expressed as mg AA equivalence per g plant material extracted). cardiac glycosides, phytosterols and triterpenoids.

Antioxidant capacity (expressed as ascorbic acid equivalence) for the kale and spirulina extracts are presented in Table 1. The antioxidant capacity ranged from levels below the detection sensitivity of the assay (ethyl acetate extracts of both kale and spirulina) to a high of approximately $10 \mathrm{mg}$ ascorbic acid equivalence per gram of dried plant material extracted (methanolic kale extract). In general, the kale extracts had substantially higher antioxidant capacities than the spirulina extracts. There was no clear correlation between the solvent used for extraction and the antioxidant capacity. For kale, the methanolic extract had a substantially higher antioxidant capacity than the aqueous extract, whereas this trend was reversed for spirulina.

\section{Antimicrobial activity}

Aliquots $(10 \mu \mathrm{l})$ of each extract were tested in the disc diffusion assay against a panel of bacterial pathogens (Figure 1). Both the kale and spirulina methanolic and aqueous extracts displayed noteworthy growth inhibitory activity against $P$. mirabilis (both the reference and clinical isolate strains). In contrast (with the exception of the methanolic and aqueous spirulina extracts, which displayed low levels of inhibitory activity against $E$. coli), the extracts were devoid of growth inhibitory activity against the other bacterial species tested. The spirulina extracts were generally better bacterial growth inhibitors than the equivalent kale extracts. This is particularly evident for the aqueous spirulina and kale extracts against $P$. mirabilis (ZOIs of 9.2 and $7.3 \mathrm{~mm}$ respectively against the reference strain).

The relative level of antimicrobial activity was further evaluated by determining the MIC values (Table 2) against the bacterial pathogens. The kale and spirulina aqueous extracts were particularly effective at inhibiting microbial growth, with low MIC values recorded against $P$. mirabilis, indicating the potent antimicrobial activity of these extracts. The aqueous spirulina extract was particularly strong (LD MIC values of 220 and $320 \mu \mathrm{g} / \mathrm{mL}$ against the reference and clinical strains respectively), compared to the aqueous kale extract (LD MIC values of $754 \mu \mathrm{g} / \mathrm{mL}$ against both the reference and clinical $P$. mirabilis strains). The methanolic extracts also had noteworthy inhibitory activity, although the methanolic kale extract (LD MIC values of 965 and

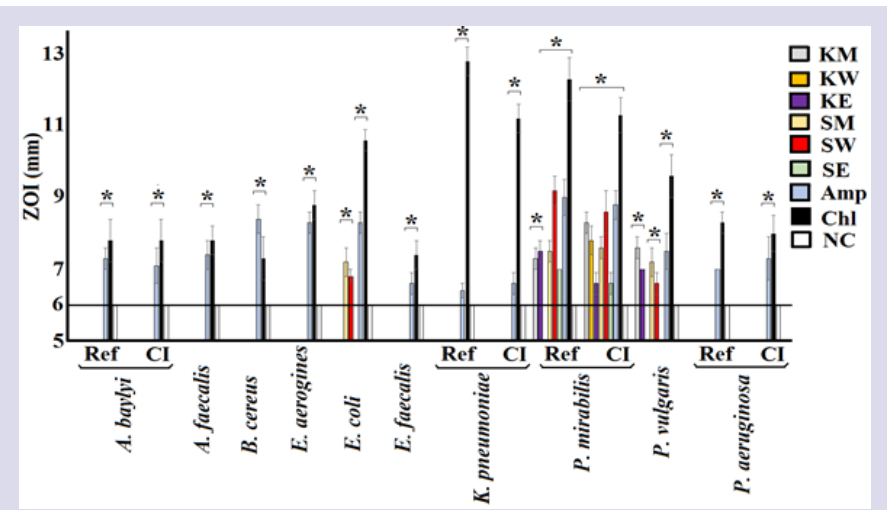

Figure 1: Antibacterial activity of kale and spirulina extracts and ampicillin and chloramphenicol controls $(10 \mu \mathrm{g})$ measured as zones of inhibition $(\mathrm{mm})$ against bacterial pathogens. Results are expressed as mean \pm SEM of at least triplicate determinations. Ref = reference strains; $\mathrm{Cl}=$ clinical isolate strains; $\mathrm{K}=$ kale; $\mathrm{S}=$ spirulina; $\mathrm{M}=$ methanolic extract; $\mathrm{W}=$ aqueous extract; $\mathrm{E}=$ ethyl acetate extract; $\mathrm{Amp}=$ ampicillin' $\mathrm{Chl}=$ chloramphenicol; $\mathrm{NC}=$ negative control. ${ }^{*}=$ results that are significantly different to the negative control. $6 \mathrm{~mm}$ line indicates the diameter of the disc. 
Table 2: Minimum inhibitory concentrations $(\mu \mathrm{g} / \mathrm{mL})$ of kale and spirulina fruit extracts against susceptible microbial species.

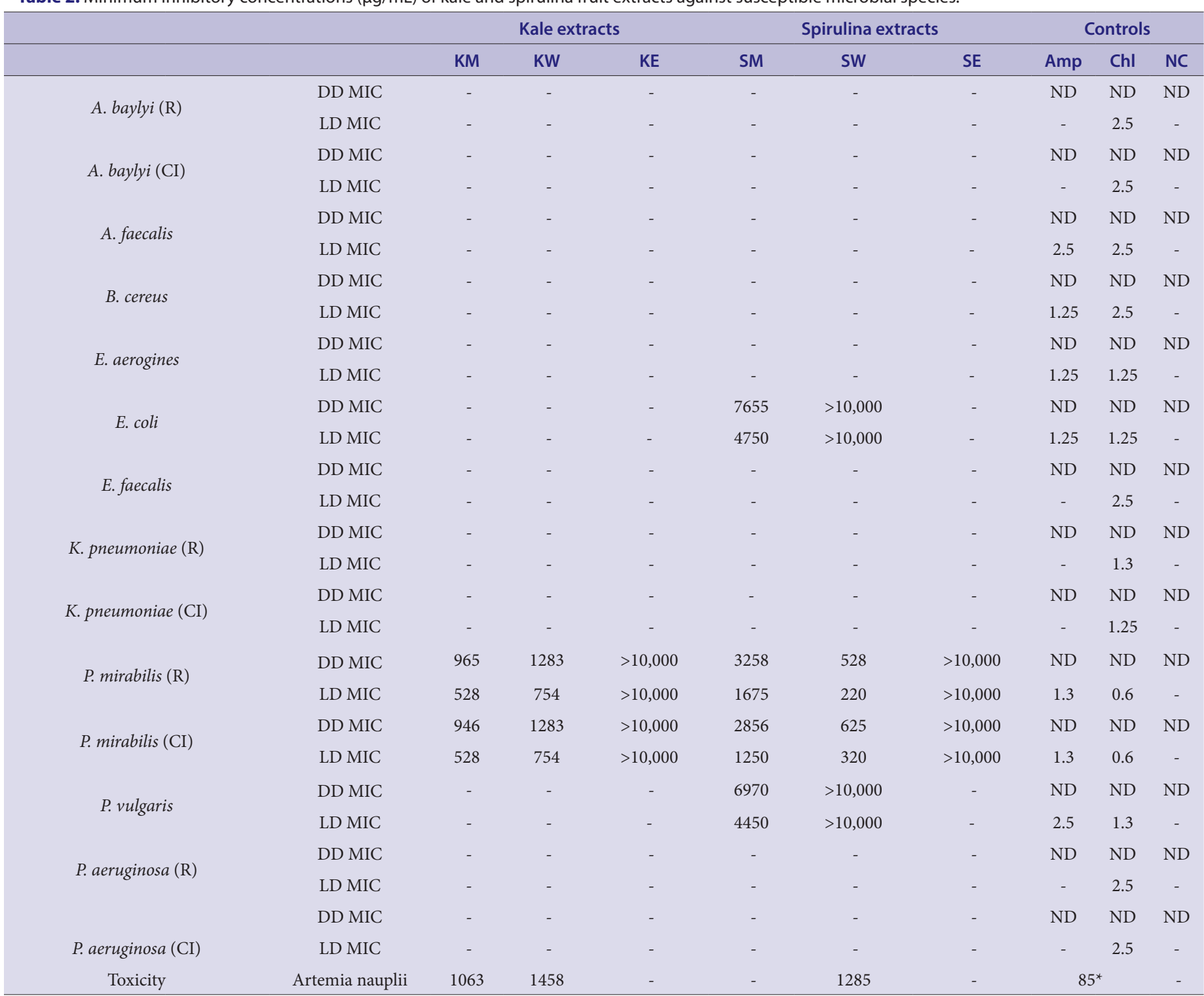

Numbers indicate the mean MIC values of triplicate determinations expressed in $\mu \mathrm{g} / \mathrm{mL} . \mathrm{KM}=$ kale methanolic extract; $\mathrm{KW}=\mathrm{kale}$ aqueous extract, $\mathrm{KE}=\mathrm{kale}$ ethyl acetate extract; $\mathrm{SM}=$ spirulina methanolic extract; $\mathrm{SW}=$ spirulina aqueous extract; $\mathrm{SE}=$ spirulina ethyl acetate extract; $\mathrm{DD}=$ disc diffusion; $\mathrm{LD}=$ liquid dilution; $\mathrm{ND}$ $=$ MIC values were not determined as only a single dose was screened; - indicates no inhibition (or toxicity) at any concentration tested; ${ }^{*}=$ potassium dichromate was used as the positive control. Bold text indicates noteworthy MIC values.

$946 \mu \mathrm{g} / \mathrm{mL}$ against the reference and clinical strains respectively) was a substantially better inhibitor of $P$. mirabilis growth than the methanolic spirulina extract (LD MIC values of 3258 and $2856 \mu \mathrm{g} / \mathrm{mL}$ against the reference and clinical strains respectively). All other bacteria were either completely resistant to the kale and spirulina extracts, or displayed only low inhibitory activity (as judged by MIC values).

\section{Quantification of toxicity}

The kale and spirulina extracts were diluted to $4000 \mu \mathrm{g} / \mathrm{mL}$ (to give a bioassay concentration of $2000 \mu \mathrm{g} / \mathrm{mL}$ ) in artificial seawater for toxicity testing in the Artemia nauplii lethality bioassay. For comparison, the reference toxin potassium dichromate was also tested in the bioassay. Potassium dichromate was rapid in its induction of mortality, with mortality evident within 4 hrs of exposure (unpublished results). The kale and spirulina extracts were slower at inducing mortality, with $\geq 12$ hrs needed for mortality induction. Despite the slower onset of mortality, the methanolic and aqueous kale extracts, as well as the aqueous spirulina extract, induced mortality significantly above that of the artificial seawater control (Figure 2). Table 2 shows the extract and control toxin concentrations required to achieve $50 \%$ mortality $\left(\mathrm{LC}_{50}\right)$ at $24 \mathrm{~h}$. As toxicity of crude plant extracts has previously been defined as 24 $\mathrm{LC}_{50}$ values $<1000 \mu \mathrm{g} / \mathrm{mL}^{47,48}$ the measured $\mathrm{LC}_{50}$ values indicate that all of the extracts were nontoxic.

\section{DISCUSSION}

The discovery of penicillin by Alexander Fleming approximately 100 years ago revolutionised medical science and provided an effective treatment against a wide variety of bacterial pathogens, thereby saving countless lives globally (as reviewed by [16]). Unfortunately, bacteria rapidly developed resistance to penicillin and by evolving to produce $\beta$-lactamase enzymes that degrade the $\beta$-lactam structure, 


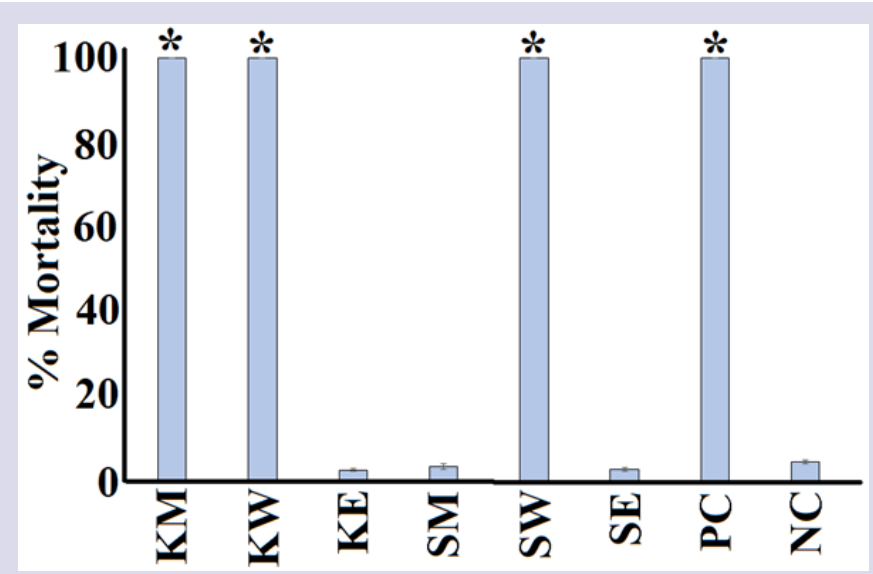

Figure 2: The lethality of kale and spirulina extracts $(2000 \mu \mathrm{g} / \mathrm{ml})$ and potassium dichromate control $(1000 \mu \mathrm{g} / \mathrm{mL})$ towards Artemia franciscana nauplii after $24 \mathrm{hrs}$ exposure. Results are expressed as mean \pm SEM of at least triplicate determinations. * indicates results that are significantly different to the untreated control $(p<0.01)$.

rendering those antibiotics ineffective or of low efficacy against many bacterial pathogens (as reviewed by [16]). Since then, numerous other antibiotic molecules of different classes (aminoglycosides, carbapenems, cephalosporins, fluoroquinolones, glycopeptides, macrolides, monobactams, oxazolidinones, rifamycins, solfonamides, streptogramins and tetracyclines) have been isolated from microbes and have been incorporated into our clinical antibacterial pharmacopeia. Furthermore, synthetic chemists have modified the scaffold structures of the naturally occurring antibiotics to increase the number, efficacy and bioavailability of antibiotics available to treat bacterial infections. However, bacteria have rapidly evolved resistance mechanisms that specifically target antibiotics, rendering them resistant to their effects. There are now limited therapeutic options against many of these resistant bacterial strains and new effective antibiotic therapies are urgently needed. Indeed, the World Health Organisation (WHO) considers the development of alternative antibiotic chemotherapies to be one of the most urgent challenges for medical science (as reviewed by [16]).

A re-examination or traditional plant-based foods and medicines is a promising approach to develop new antibiotic chemotherapies. Plantbased medicines were commonly used in many cultures to treat bacterial infections before the discovery of penicillin and are still used in several traditional healing systems such as Ayurveda, or Traditional Chinese Medicine (TCM). The use of these traditional medicines is often well documented, making the selection of species for study relatively easy. Furthermore, plant preparations often contain multiple anti-pathogenic compounds, providing greater efficacy and decreasing the possibility of inducing further bacterial resistance.

The high antioxidant capacities and presence of bioactive secondary components in some 'superfoods' makes them targets for the discovery of new antibacterial chemotherapies. Both kale and spirulina have high antioxidant contents and are rich in Vitamins A, C, B1, B2, B6, E, folate and pantothenic acid, as well as iron, calcium, potassium, phosphates and manganese. Despite this, neither kale nor spirulina have been rigorously evaluated for antibacterial activity. Notably, our screening studies determined that both kale and spirulina extracts had limited specificity against the bacterial pathogens screened. The kale and spirulina extracts were particularly good inhibitors of $P$. mirabilis. This is noteworthy as P. mirabilis has been implicated in urinary tract infections (UTI's) and the induction of rheumatoid arthritis (RA). ${ }^{50}$ Thus, consumption of kale or spirulina has the potential to block RA before the induction of the immune response and inflammation, thus not only blocking the late phase symptoms, but also the tissue damage associated with RA. The methanolic spirulina extract also inhibited the growth of E. coli, although the MIC values indicate only weak inhibition. All extracts were completely ineffective against all other bacterial species tested, indicating a narrow specificity for these extracts.

The results of this study indicate that the kale and spirulina extracts examined in this report are worthy of further study due to their $P$. mirabilis inhibitory activity. The aqueous spirulina extract was particularly promising. Furthermore, as extracts with $\mathrm{LC}_{50}$ values greater than $1000 \mu \mathrm{g} / \mathrm{mL}$ in the Artemia nauplii bioassay have been defined as being non-toxic, ${ }^{47,48}$ all extracts were deemed to be non-toxic. Further evaluation of the antimicrobial and anticancer properties of the kale and spirulina extracts is warranted. Likewise, further bioactivity driven purification studies are needed to examine the mechanisms of action of these agents.

\section{CONCLUSION}

The results of this study demonstrate that the aqueous spirulina and kale extracts are good inhibitors of $P$. mirabilis growth, yet were ineffective against the other bacterial species tested. Bioactivity driven purifications of the active components and an examination of the mechanisms of action of these agents is required.

\section{ACKNOWLEDGEMENT}

The authors are grateful to Michelle Mendell and Jane Gifkins of Griffith University for providing the clinical bacterial strains used in this study. Financial support for this work was provided by the Environmental Futures Research Institute and the School of Environment and Science, Griffith University, Australia.

\section{CONFLICT OF INTEREST}

The authors report no conflicts of interest.

\section{ABBREVIATIONS}

DMSO: Dimethyl sulfoxide; $\mathbf{L C}_{50}$ : The concentration required to achieve 50 \% mortality; MIC: Minimum inhibitory concentration; ZOI: Zone of inhibition.

\section{REFERENCES}

1. Kamboj VP. Herbal medicine. Curr Sci. 2000;78(1):35-9.

2. Hostettmann K, Hamburger M. Search for new lead compounds of natural origin. In Perspectives in Medical Chemistry. Verlag Helvitica Acta, Basel. 1993.

3. Wright MH, Sirdaarta J, White A, et al. GC-MS headspace analysis of Terminalia ferdinandiana fruit and leaf extracts which inhibit Bacillus anthracis growth. Pharmacogn J. 2017;9(1):73-82. DOI: 10.5530/pj.2017.1.14

4. Mpala LN, Chikowe GR, Cock IE. Growth inhibitory properties of extracts prepared from selected Leptospermum and Melaleuca species against a panel of pathogenic bacteria. Pharmacogn Commn. 2016;6(4):215-24. DOI: 10.5530/ pc. 2016.4 .4

5. Omer E, Elshamy Al, Nassar M, et al. Plantago squarrosa Murray extracts inhibit the growth of some bacterial triggers of autoimmune diseases: GC-MS analysis of an inhibitory extract. Inflammopharmacol. 2018;27(2):373-85. DOI: 10.1007/s10787-018-0547-0

6. Newman DJ, Cragg GM, Snader KM. The influence of natural products on drug discovery. Nat Prod Rep. 2000;17(3):215-34.

7. Gaillot C, Sirdaarta J, Cock IE. Examination of the antimicrobial and anticancer properties of mangosteen. Acta Hortic. 2016;1106:231-8

8. Wright MH, Greene AC, Cock IE. Investigating the pharmacognostic potential of Indian Terminalia spp. in the treatment and prevention of yersiniosis. Pharmacogn Commn. 2017;7(3):108-13. DOI: 10.5530/pc.2017.3.16

9. Gilani AH, Atta-ur-Rahman. Trends in ethnopharmacology. J Ethnopharmacol. 2005; 100(1-2):43-9.

10. Hübsch Z, ZyI RLV, Cock IE, et al. Interactive antimicrobial and toxicity profiles of 
conventional antimicrobials with Southern African medicinal plants. S Afr J Bot. 2014;93:185-97. DOI: 10.1016/j.sajb.2014.04.005

11. Cock IE, Vuuren SFV. Anti-Proteus activity of some South African medicinal plants: Their potential for the treatment and prevention of rheumatoid arthritis. Inflammopharmacol. 2014:22(1):23-36. DOI 10.1007/s10787-013-0179-3.

12. Omer E, Elshamy A, EIGendy AN, et al. Cakile maritima Scop. Extracts inhibit the growth of some bacterial triggers of autoimmune diseases: GC-MS analysis of an inhibitory extract. Pharmacog J. 2016;8(4):361-74. DOI: 10.5530/pj.2016.4.9

13. Biggs I, Sirdaarta J, White A, et al. GC-MS analysis of Commiphora molmol oleo-resin extracts which inhibit the growth of bacterial triggers of selected autoimmune diseases. Pharmacog J. 2016;8(3):191-202. DOI: 10.5530/ pj.2016.3.4

14. Biggs I, Sirdaarta J, White A, et al. GC-MS analysis of frankincense extracts which inhibit the growth of bacterial triggers of selected autoimmune diseases. Pharmacog Commn. 2016;6(1):10-22. DOI: 10.5530/pc.2016.1.3

15. Fernandez A, Cock IE. Tabebuia impetiginosa (Mart. Ex DC. Mattos) bark extracts inhibit the growth of gastrointestinal bacterial pathogens and potentiate the activity of some conventional antibiotics. Pharmacogn Commn. 2020;10(2):7582. DOI: $10.5530 / p c .2020 .2 .15$

16. Cheesman MJ, Ilanko A, Blonk B, et al. Developing new antimicrobial therapies: Are synergistic combinations of plant extracts/compounds with conventional antibiotics the solution?. Pharmacogn Rev. 2017;11(22):57-72. DOI: 10.4103/ phrev.phrev_21_17

17. WHO. Antimicrobial Resistance. World Health Organization. 2016. Available from: http://www.who.int/mediacentre/factsheets/fs194/en/. [Cited on 2019 May 10].

18. Sirdaarta J, Matthews B, Cock IE. Kakadu plum fruit extracts inhibit the growth of the bacterial triggers of rheumatoid arthritis: Identification of stilbene and tannin components. J Funct Food. 2015;17:610-20. DOI: 10.1016/j.jff.2015.06.019

19. Ilanko A, Cock IE. The interactive antimicrobial activity of contentional antibiotics and Petalostigma spp. extracts against bacterial triggers of some autoimmune inflammatory diseases. Pharmacogn J. 2019;11(2):292-309. DOI: 10.5530/ pj.2019.11.45

20. Winnett V, Sirdaarta J, White A, et al. Inhibition of Klebsiella pneumonia growth by selected Australian plants: Natural approaches for the prevention and management of ankylosing spondylitis. Inflammopharmacol. 2017;25(2):22335. DOI: 10.1007/s10787-017-0328-1

21. Cheesman M, White A, Matthews B, et al. Terminalia ferdinandiana fruit and leaf extracts inhibit methicillin-resistant Staphylococcus aureus growth. Planta Medica. 2019;85(16):1253-62. DOI: 10.1055/a-1013-0434

22. Cock IE, Vuuren V. The traditional use of southern African medicinal plants for the treatment of bacterial respiratory diseases: A review of the ethnobotany and scientific evaluations. J Ethnopharmacol. 2020;27:113204. DOI: 10.1016/j. jep.2020.113204

23. Courtney R, Sirdaarta J, Matthews B, et al. Tannin components and inhibitory activity of Kakadu plum leaf extracts against microbial triggers of autoimmune inflammatory diseases. Pharmacogn J. 2015;7(1):18-31. DOI: 10.5530/ pj.2015.7.2

24. Wright MH, Sirdaarta J, Matthews B, et al. Growth inhibitory activity of Kakadu plum extracts against the opportunistic pathogen Clostridium perfringens: New leads in the prevention and treatment of clostridial myonecrosis. Pharmacogn J. 2016;8(2):144-54. DOI: 10.5530/pj.2016.2.8

25. Tiwana G, Cock IE, White A, et al. Use of specific combinations of the triphala plant component extracts to potentiate the inhibition of gastrointestinal bacterial growth. J Ethnopharmacol. 2020;112937.s DOI: 10.1016/j.jep.2020.112937

26. Mandeville A, Cock IE. Terminalia chebula Retz. fruit extracts inhibit bacterial triggers of some autoimmune diseases and potentiate the activity of tetracycline. Indian J Microbiol. 2018;58(4):496-506. DOI: 10.1007/s12088-0180754-9

27. Arkhipov A, Sirdaarta J, Rayan $P$, et al. An examination of the antibacterial, antifungal, anti-Giardial and anticancer properties of Kigelia africana fruit extracts. Pharmacogn Commun. 2014;4(3):62-76. DOI: 10.5530/pc.2014.3.7

28. Ilanko P, McDonnell PA, Vuuren SFV, et al. Interactive antibacterial profile of Moringa oleifera Lam. Extracts and conventional antibiotics against bacterial triggers of some autoimmune inflammatory diseases. S Afr J Bot. 2019:124:420-35.

29. Lee CJ, Wright MH, Arnold MSJ, et al. Inhibition of Streptococcus pyogenes growth by native Australian plants: New approaches towards the management of impetigo, pharyngitis and rheumatic heart disease. Pharmacogn Commun. 2016;6(3):164-73. DOI: 10.5530/pc.2016.3.6
30. Wright MH, Sirdaarta J, White A, et al. GC-MS headspace analysis of Terminalia ferdinandiana fruit and leaf extracts which inhibit Bacillus anthracis growth. Pharmacogn J. 2017;9(1):73-82. DOI: 10.5530/pj.2017.1.14

31. McManus $\mathrm{K}$, Wood A, Wright MH, et al. Terminalia ferdinandiana Exell. extracts inhibit the growth of body odour-forming bacteria. Internat J Cosmetic Sci. 2017;39(5):500-10. DOI: 10.1111/ics.12403

32. Hutchings A, Cock IE. An interactive antimicrobial activity of Embelica officinalis Gaertn. Fruit extracts and conventional antibiotics against some bacterial triggers of autoimmune inflammatory diseases. Pharmacogn J. 2018;10(4):65462. DOI: $10.5530 /$ pj.2018.4.108

33. Hertog MG, Bueno-de-Mesquita HB, Fehily AM, Sweetnam PM, Elwood PC, Kromhout $D$. Fruit and vegetable consumption and cancer mortality in the caerphilly study. Cancer Epidemiol Biomarkers Prev. 1996;5(9):673-7.

34. Vita JA. Polyphenols and cardiovascular disease: Effects on endothelial and platelet function. Am J Clin Nutrit. 2005;81(1):292S-7S.

35. Youdim KA, Spencer JPE, Schroeter H, Rice-Evans CA. Dietary flavonoids as potential neuroprotectans. Biol Chem. 2002;383(3-4):503-19.

36. Tsuda T, Horio F, Uchida K, Aoki H, Osawa T. Dietary cyanidin 3-O-b- D-glucosiderich purple corn colour prevents obesity and ameliorates hyperglycemia in mice. J Nutr. 2003;133:2125-30.

37. Rice-Evans C, Miller N, Paganga G. Antioxidant properties of phenolic compound. Trends Plant Sci. 1997;2(4):152-9.

38. US Department of Agriculture. Food data central. 2020. https://fdc.nal.usda. gov/ cited 20 October 2020

39. Wright MH, Matthews B, Arnold MSJ, et al. The prevention of fish spoilage by high antioxidant Australian culinary plants: Shewanella putrefaciens growth inhibition. Internat J Food SciTechnol. 2016;51(3):801-13. DOI: 10.1111/ijfs.13026

40. Rayan $\mathrm{P}$, Matthews $\mathrm{B}, \mathrm{McD}$ onnell $\mathrm{PA}$, et al. Terminalia ferdinandiana extracts as inhibitors of Giardia duodenalis proliferation: A new treatment for giardiasis. Parasitol Res. 2015;114(7):2611-20. DOI: 10.1007/s00436-015-4465-4

41. Noé W, Murhekar S, White $A$, et al. Inhibition of the growth of human dermatophytic pathogens by selected Australian and Asian plants traditionally used to treat fungal infections. Journal de Mycologie Médicale. 2019;29(4):33144. DOI: 10.1016/j.mycmed.2019.05.003

42. Shalom J, Cock IE. Terminalia ferdinandiana Exell. fruit and leaf extracts inhibit proliferation and induce apoptosis in selected human cancer cell lines. Nutrit Cancer. 2018;70(4):579-93. DOI: 10.1080/01635581.2018.1460680

43. Wright MH, Sirdaarta J, White A, et al. GC-MS headspace analysis of Terminalia ferdinandiana fruit and leaf extracts which inhibit Bacillus anthracis growth. Pharmacogn J. 2017;9(1):73-82. DOI: 10.5530/pj.2017.1.14

44. Cock IE, Wright MH, Matthews $\mathrm{B}$, et al. Bioactive compounds sourced from Terminalia spp. in bacterial malodour prevention: An effective alternative to chemical additives. Internat J Cosmetic Sci. 2019;41(5):496-508. DOI: 10.1111/ ics. 12567

45. Hutchings A, Cock IE. An interactive antimicrobial activity of Embelica officinalis Gaertn. Fruit extracts and conventional antibiotics against some bacterial triggers of autoimmune inflammatory diseases. Pharmacogn J. 2018;10(4):65462. DOI: $10.5530 /$ pj.2018.4.108

46. Rabadeaux $C$, Vallette $L$, Sirdaarta J, et al. An examination of the antimicrobial and anticancer properties of Khaya senegalensis (Desr.) A. Juss. bark extracts. Pharmacogn J. 2017;9(4):504-18. DOI: 10.5530/pj.2017.4.82

47. Cock IE, Ruebhart DR. Comparison of the brine shrimp nauplii bioassay and the ToxScreen-II test for the detection of toxicity associated with Aloe vera (Aloe barbadensis Miller) leaf extract. Pharmacogn Res. 2009;1(2):98-101.

48. Ruebhart DR, WickramasingheW, Cock IE. Protective efficacy of the antioxidants vitamin $\mathrm{E}$ and Trolox against Microcystis aeruginosa and microcystin - LR in Artemia franciscana nauplii. J Toxicol Environ Health Part A. 2009;72(24):156775. DOI: 10.1080/15287390903232459

49. Wright MH, Shalom J, Matthews B, et al. Terminalia ferdinandiana Exell. extracts inhibit Shewanella spp. growth and prevent fish spoilage. Food Microbiol. 2019;78:114-22. DOI: 10.1016/j.fm.2018.10.006

50. Cock IE, Vuuren SFV. Anti-Proteus activity of some South African medicinal plants: Their potential for the treatment and prevention of rheumatoid arthritis. Inflammopharmacol. 2014;22(1):23-36. DOI 10.1007/s10787-013-0179-3. 


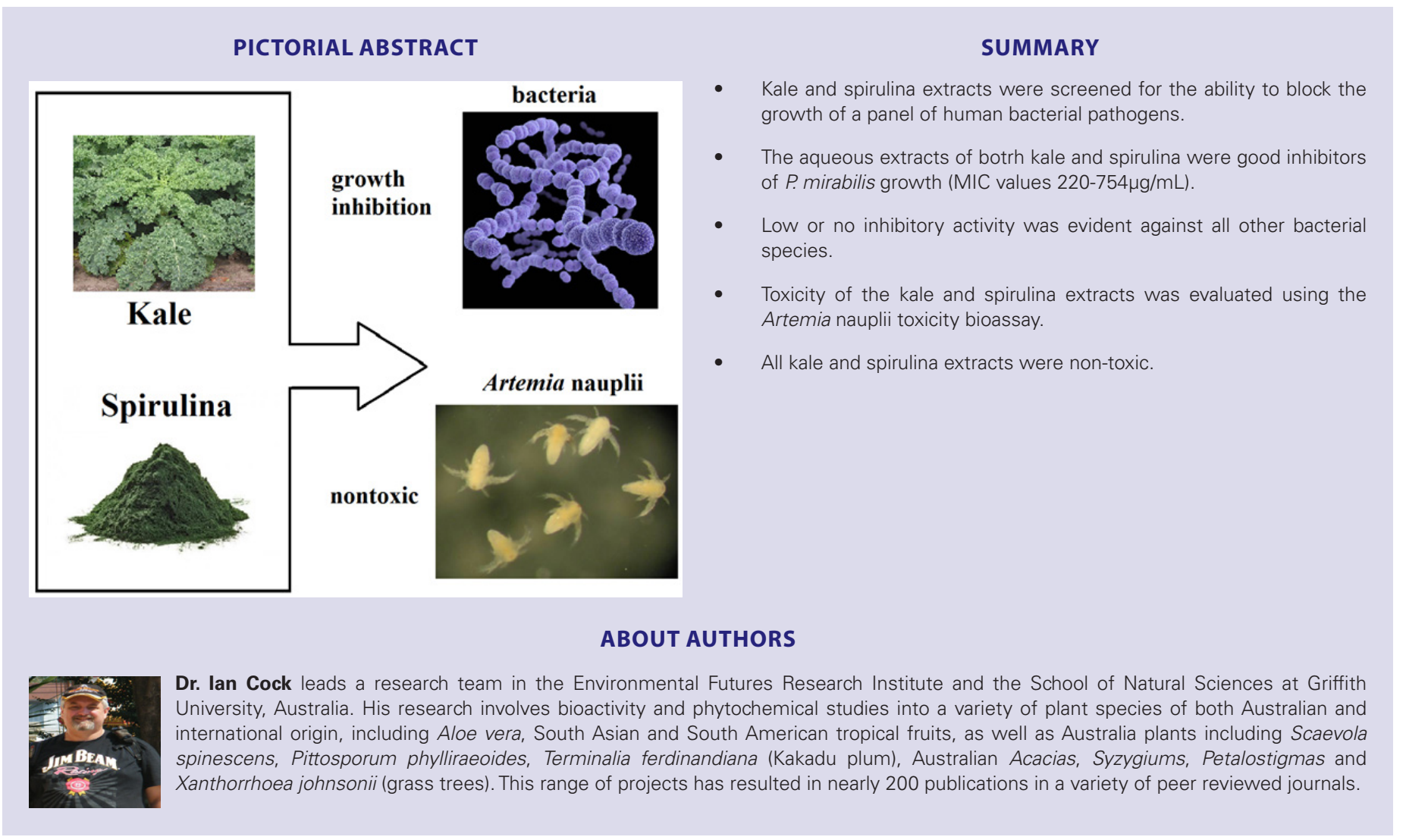

